ORIGINAL ARTICLE

\title{
Is risk of fast bowling injury in cricketers greatest in those who bowl most? A cohort of young English fast bowlers
}

\author{
P L Gregory, M E Batt, W A Wallace
}

Br J Sports Med 2004;38:125-128. doi: 10.1136/bjsm.2002.000275

See end of article for authors' affiliations

Correspondence to: Dr Gregory, Centre for Sports Medicine, Orthopaedic and Accident Surgery, C Floor West Block, Queen's Medical Centre, University Hospital, Nottingham NG7 2UH, UK; peter.gregory@ nottingham.ac.uk

Accepted 5 March 2003
Objectives: To determine whether young fast bowlers are exceeding directives limiting bowling and how incidence of fast bowling injury varies with amount of bowling.

Methods: A prospective cohort study of injuries sustained by 70 fast bowlers (mean (SD) age 15.3 (2.4) years) was undertaken. Bowlers were recruited from the Centres of Excellence of three "First Class" counties in England in January 1998. Details of injuries were collected by telephone questionnaire every six weeks for six months from each bowler. The number of balls bowled in matches and practices by each bowler was recorded. The cohort was divided into groups according to the number of balls bowled in the study period, and bowling injury incidences were calculated for each group.

Main outcome measures: All injuries caused by bowling and interfering with bowling.

Results: Telephone follow up was achieved when planned on $97.9 \%$ of occasions. There were 23 bowling injuries reported in the study period that met the inclusion criteria. The overall incidence of bowling injury in the study period was 32.8 per 100 fast bowlers. The incidence of bowling injury for the 15 bowlers who bowled less than 1000 balls in the study period was 20.0 per 100 fast bowlers. The incidence for the 32 who bowled 1000-2000 balls was 37.5 per 100 fast bowlers. The incidence for the 14 who bowled 2000-3000 balls was 35.7 per 100. The incidence for the nine who bowled more than 3000 balls was 33.3 per 100 .

Conclusions: The expected increased incidence of bowling injury in young fast bowlers who bowl most was not observed, although more than $12 \%$ exceeded the recommended limit. l: njuries in first league and provincial cricketers and in schoolboy cricketers in South Africa have been reported to have a seasonal incidence of $49 \% .^{12}$ Injuries occurred in one of the three phases of play: batting, bowling, or fielding. Most occurred in bowling in both first league and provincial cricketers (42\%) and in schoolboy cricketers $(47.4 \%)$. Over $40 \%$ of injuries occurred during fielding in first league and provincial cricketers, and nearly $30 \%$ of injuries occurred during batting in schoolboys. Hand injuries occur as a result of being struck by the ball when fielding, and professionals are more likely to sustain hand injuries while batting. ${ }^{3}$ Incidence of acute injuries in general in professional cricket in England is reported as 57.4 per 1000 days. Nearly 45\% of injuries were to the lower limb in this cohort of county players. Incidence of injury was higher in bowlers than in allrounders, batsmen, or wicketkeepers. The fast bowlers sustained more muscle/tendon injuries than other players. ${ }^{4}$

Back injuries in fast bowlers were studied in the 1980s and 1990s. Harris ${ }^{5}$ studied 99 South African cricketers (mean age 20.2 years) and found the prevalence of low back pain to be $75.6 \%$ in 37 fast bowlers. Foster $e^{2}$ al $^{6}$ found that bowlers who bowled in more than 17 matches, the mean number in a study of 82 young fast bowlers, had a higher prevalence $(58 \%)$ of stress fracture and soft tissue back injury than the other bowlers $(38 \%)$. Elliott et $\mathrm{al}^{7}$ found that bowlers with spinal abnormalities were significantly older than those without. They did not report the amount of bowling by their subjects, but postulated "a greater tendency to display abnormal radiologic features with more years of bowling". The England and Wales Cricket Board (ECB) issued draft directives ${ }^{8}$ in 1992 that restrict the number of balls bowled by young fast bowlers in matches and training and discourage mixed bowling techniques. Table 1 shows the directives on amount of bowling. The kinematics of mixed bowling techniques, which have been described by Foster et al, ${ }^{6}$ have been implicated in disc degeneration ${ }^{9}{ }^{10}$ and stress fractures of the pars interarticularis. ${ }^{6711}$ Restricting fast bowling and reducing the use of the mixed bowling technique are expected to reduce overuse back injuries.

The directives of the ECB focus only on the problem of back injury in fast bowlers. There are no published studies that relate the overall morbidity attributed to fast bowling to the amount of bowling. This information would be useful to predict the impact of the bowling restrictions imposed by the ECB.

We hypothesised that some young fast bowlers exceed the ECB directives on the amount of bowling and that the bowlers who bowl most have the highest incidence of injury. A power study indicated that to detect a difference of between 10 and 50 injuries per 100 bowlers, 64 subjects would be needed per group at $80 \%$ power and a significance level of 5\%. Preliminary inquiries suggested that this number of fast bowlers would be coached at three County Cricket Centres of Excellence during the 1998 season. Thus a cohort of young cricketers, recruited at these Centres of Excellence, was studied to determine how incidence of fast bowling injury in young cricketers varies with the amount of bowling.

\section{METHODS}

Coaches introduced us to all fast bowlers attending three English County Cricket Club Centres of Excellence in January 1998. The coaches had determined the standard of these bowlers to be high enough to expect them to bowl for their county in representative cricket matches during the 1998 season. This assessment had been made in a system of offseason trials which supplemented the coaches' knowledge of past performances of the bowlers. The ECB defines a fast bowler as one for whom the wicketkeeper stands back. ${ }^{8}$ There were 72 such bowlers. They were asked if they were willing to take part in this study. Two refused, believing it would take 
Table 1 Directives on fast bowling from the England and Wales Cricket Board

\begin{tabular}{llll}
\hline Age (years) & Matches & Practices & $\begin{array}{l}\text { Maximum of } \\
\text { matches+practices in } 1 \text { week }\end{array}$ \\
\hline Under 13 & 2 spells of $3-4$ overs & 2 per week; 30 balls $/$ session & 3 \\
Under 15 & 2 spells of $4-5$ overs & 2 per week; 36 balls $/$ session & 3 \\
Under 17 & 3 spells of $4-5$ overs & 3 per week; 36 balls $/$ session & 4 \\
Under 19 & 3 spells of $5-6$ overs & 3 per week; 42 balls $/$ session & 4 \\
Senior & 3 spells of $6-8$ overs & 3 per week; 48 balls $/$ session & \\
\hline
\end{tabular}

up too much of their time. Thus 70 fast bowlers were recruited.

All 70 were interviewed and examined by the first author when recruited and followed up by telephone questionnaire every six weeks for six months. This included three months of preseason (indoor) training and the first three months of the 1998 cricket season. The bowlers used a logbook to record details and to aid recall. They stated how many overs and extra balls they bowled in each match. In addition, they provided an estimate of the time they spent practicing bowling in the nets and the number of other bowlers sharing the nets. The number of balls bowled by any one bowler in a unit of time of net practice is inversely proportional to the number of bowlers in that net. The number of balls bowled in 18 five minute periods of observed net sessions averaged 22 . This average was used to calculate the number of balls by individual bowlers during net sessions. From this information, the total number of balls bowled in matches and practices (nets) was calculated:

No of balls bowled in a net session $=($ time bowling in net $(\min ) /$ No of bowlers sharing nets $) \times 22$.

Injuries, defined as painful or disabling conditions, also occur during batting and fielding, but only bowling injuries are presented in this study. The first author asked the fast bowlers to report all bowling injuries during the telephone questionnaire. These injuries were not investigated, although reports of attending doctors and physiotherapists were used in recording the diagnosis. Injuries were graded according to the highest grade into which they could be classified (table 2). Reporting of minor injuries is likely to vary. Grade I and II injuries do not impair bowling performance or prevent bowling and are more likely to be subject to such reporting bias. Therefore these grades were excluded from the analysis.

Microsoft Excel (Redland, Washington, USA) was used to store and analyse the data. Injury incidence was calculated as injuries per 100 bowlers: (No of new cases in a fixed period/ No of people exposed) $\times 100$. A weighted $\chi^{2}$ test (SPSS, Chicago, Illinois, USA) was used to determine if there were differences between injury rates per 100 bowlers.

\section{RESULTS}

The range of ages of these fast bowlers was 9-21 years, and ages were normally distributed with a mean (SD) of 15.3 (2.4) years. Heights, with a range of $1.40-1.90 \mathrm{~m}$, and body mass, with a range of $30-90 \mathrm{~kg}$, were also normally distributed. The mean (SD) height was $1.71(0.14) \mathrm{m}$ and mean (SD) body mass was $62.6(14.5) \mathrm{kg}$. The mean of the body mass index (body mass $/$ height $^{2}$ ) was $21.1(2.5) \mathrm{kg} / \mathrm{m}^{2}$.

Table 2 Classification of injury severity

Grade I Pain after bowling

Grade II Pain during bowling

Grade III Pain impairing bowling performance

Grade IV Pain preventing bowling
The 70 fast bowlers were followed up for a mean of 174.2 days; none dropped out of the study. No bowler was contacted less than three times. The mean time between contacts was 43.3 days.

During the study, 23 bowling injuries that were of a severity that interfered with bowling (grade III or IV) were reported. All injuries were new. The overall incidence of grade III or IV bowling injuries during the study period was 32.8 per 100 fast bowlers. The incidence at the various anatomical sites was 11.4 at the knee, 8.6 at the ankle, and 5.7 at the low back. For shoulder, thigh, calf, groin, and ribs, the incidence was 1.4 per 100 fast bowlers at each site. Five of the six grade III or IV fast bowling ankle injuries were sprains, and all eight knee injuries of this severity were overuse type problems (five patellofemoral pain syndrome with no obvious trauma at onset, two Osgood-Schlatter's disease, and one patellar tendinitis). Low back pain (all grades) was reported by $10 \%$ of the bowlers during the study period. Grade IV low back pain occurred in three bowlers. One of these, a 13 year old, had a pars interarticularis stress fracture confirmed by isotope bone scan and computed tomography.

The fast bowlers delivered a mean of 2018 balls in matches and practice in the study period. The cohort was divided into four groups according to the number of balls bowled. Table 3 details the number of bowlers in each group, the total number of balls bowled by each group, and the grade III and IV injury rate per 1000 balls bowled. There were no significant differences between the injury rates for the four groups (weighted $\chi^{2}=4.89, \mathrm{df}=3, \mathrm{p}=0.180$ ). Figure 1 presents the bowling injury incidence per 100 fast bowlers in each group.

\section{DISCUSSION}

Follow up by telephone questionnaire was satisfactory, with 97.9\% of planned contacts achieved. Repeated follow up at six week intervals was preferable to the single postal questionnaire at the end of the study period used in cricket studies of Stretch ${ }^{12}$ and Harris, ${ }^{5}$ as the bowlers had less time to forget the required details.

At recruitment, it was expected that all the fast bowlers would bowl for their county in the appropriate age group. The bowlers studied bowled $69 \%$ of balls in practice and 31\% in matches. Despite this practice, some did not develop their skill adequately to be asked to bowl regularly in matches. Those bowling less than 1000 balls in the six month study period bowled mainly in practice. They bowled less than 24 balls in matches each week of the competitive season and could justifiably be described as "occasional" bowlers. The ECB directives do not limit the amount these bowlers bowl in matches. Tighter implementation of the directives restricting more able bowlers could result in the occasional bowlers bowling more. This group had the lowest incidence of bowling injury at 20.0 per 100 bowlers. The incidence of bowling injury in those bowling more than 1000 balls in the study was 36.4 per 100 bowlers. This is not a significant difference $\left(\chi^{2}=1.43, \mathrm{p}=0.232\right)$. 


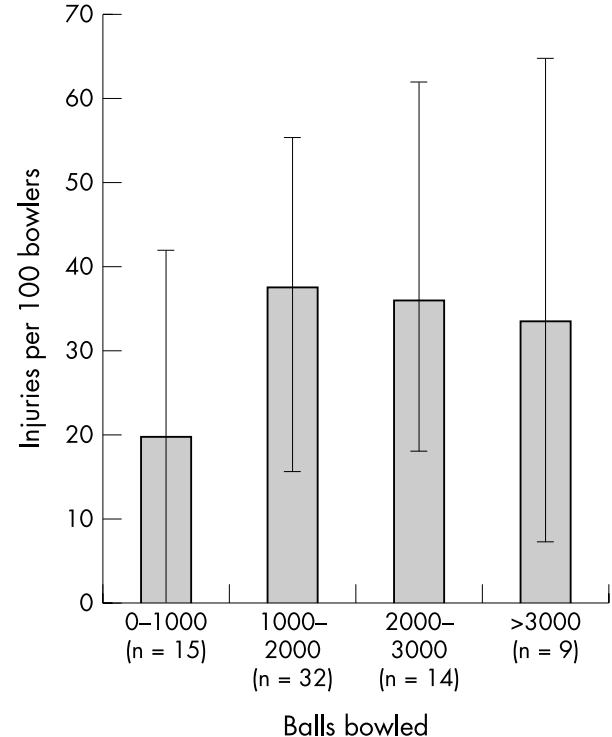

Figure 1 Incidence (95\% confidence interval) of grade III or IV fast bowling injury in six months of 1998.

At the under 15 level, the ECB directives restrict fast bowlers to 60 balls a day in three matches a week. The bowlers can replace matches with practices, but the restrictions are more stringent at 36 balls a session. Thus in our study period, the maximum bowled during the cricket season (April to July) would have been 2160 balls. In preseason training, the bowlers would have been restricted to 72 balls a week, amounting to 864 balls from January to April. The total possible within the ECB directives would have been 3024 balls. Nine bowlers in this study bowled more than 3000 balls. Undoubtedly, these bowlers all exceeded the directives on some weeks, as there were other weeks when bad weather prevented any cricket. The incidence of bowling injury in the nine who bowled more than 3000 balls was 33 per 100 bowlers. This was slightly lower than the incidence of bowling injury in the 46 who bowled between 1000 and 3000 balls, which was 37 per 100 bowlers. The difference between the percentage sustaining bowling injuries in the group bowling more than 3000 balls and the percentage in those bowling 1000-3000 balls was 3.7\% (95\% confidence interval $-30 \%$ to $29 \%$ ). These data do not therefore support the hypothesis that young fast bowlers who bowl most and exceed the directives are at greatest risk of serious bowling injury.

Harris $^{5}$ did not state the period of time over which he recorded the prevalence of low back pain. He studied cricketers who were on average five years older than those in our study. Had we studied older cricketers, the incidence of low back pain may have been higher. The cricketers studied by Harris bowled on hard South African playing surfaces, which offer less force absorption than many surfaces played on in England. This results in greater stress on the musculoskeletal structures and perhaps accounts for the high prevalence of low back pain of $75.6 \%$. In our study, only $5.7 \%$ of fast bowlers reported a grade III or IV fast bowling injury to the lower back. Stretch ${ }^{2}$ found $55.5 \%$ of bowling injuries were to the back, whereas only $17.4 \%$ of injuries in our study were to the lower back and none were to the upper back. We found that fast bowling was more likely to cause ankle sprains and injuries to the knee without obvious trauma at the onset. In the last 15 years, research has attempted to identify the cause of "fast bowlers' back". Subsequently preventive measures have been taken, and it could be that, as a consequence, we found a lower proportion of cricketers with this type of problem in our study than in previously published research.

The cohort studied is representative of promising young English fast bowlers. The English cricket season is almost six months long, and cricketers train indoors through the other six months of the year. Thus the six month study period is representative of a full year, including three months training and three months cricket season. Excellent follow up was achieved by telephone questionnaire at frequent intervals, minimising recall problems. No bowler dropped out of the study. The data provide a detailed description of the morbidity associated with fast bowling in young English cricketers. Minor injuries (grade I and II) that might have been subject to recall bias were excluded.

We acknowledge the following limitations to this study. We failed to analyse the data for confounding variables in the groups. In particular, some bowlers will have been affected by a growth spurt and some injuries may have been associated with this. However, the bowlers were exposed to a similar standard of cricket and similar climatic conditions. The results should not be generalised to bowlers in other climatic conditions where surfaces are harder and might reasonably be expected to lead to more injuries. Neither should the results be generalised to spin bowlers. The injuries of these bowlers studied simultaneously have been reported..$^{12}$ Fewer bowlers were available for recruitment than coaches had estimated, injury rates were lower than expected, and there was a smaller difference in injury incidence than we had expected when performing our power study. All these factors contribute to us being unable to find significant differences in injury incidence. It is possible that bowlers who had bowled more in the time leading up to the study period became injured and bowled less in the study period. This may have exaggerated the injury rate in the group that bowled least. This study only explores injuries occurring during the period in which the bowling load was monitored. Injuries may become manifest after the study period and yet have been related to activity during the study period. Nevertheless the bowling load in the study period is likely to be similar to the past bowling load for many of the bowlers studied. Thus some of the injuries reported may result from this past activity. This study did not consider the length of individual

Table 3 Number of bowlers, total number of balls bowled, and grade III or IV fast bowling injuries in four groups

\begin{tabular}{lllll}
\hline Bowling group & No of bowlers & $\begin{array}{l}\text { Total balls bowled } \\
\text { in study }\end{array}$ & $\begin{array}{l}\text { No of grade III } \\
\text { or IV injuries }\end{array}$ & $\begin{array}{l}\text { Grade III or IV injuries } \\
\text { per } 1000 \text { balls }\end{array}$ \\
\hline$<1000$ balls & 15 & 11628 & 3 & 0.258 \\
$1000-2000$ balls & 32 & 50847 & 12 & 0.236 \\
$2000-3000$ balls & 14 & 34013 & 5 & 0.147 \\
$>3000$ balls & 9 & 44776 & 3 & 0.067 \\
All & 70 & 141264 & 23 & 0.163 \\
\hline
\end{tabular}




\section{Take home message}

- The ECB has issued directives to restrict the amount of bowling of young fast bowlers in an attempt to reduce overuse injuries of the low back.

- Some young bowlers are exceeding these directives.

- Incidence of fast bowling injuries in general was not significantly higher in those that exceeded the directives.

spells of bowling, either in the nets or in matches. This may be an important factor if injuries occur when a bowler becomes fatigued. Diagnosis was based on the reports of attending doctors and physiotherapists, with the authors not able to examine and investigate the injuries. Assessment of bowling technique was made by coaches only, but did not involve kinematic analysis and so has been excluded from this report.

\section{Conclusions}

The data collected from this cohort of young English fast bowlers shows that more than $12 \%$ of young fast bowlers are exceeding ECB directives on amount of bowling. Yet in this study, this has not been associated with a greater risk of bowling injury. There was an increase in risk of bowling injury associated with a "regular" bowler compared with an "occasional" bowler, although statistical significance was not found. Occasional bowlers may be required to bowl more in future if ECB restrictions are implemented rigorously. Their risk of injury is likely to increase. The incidence of low back injuries in fast bowlers was much lower than in previous studies carried out in South Africa and Australia. This may be due to softer pitches in England, measures taken by the ECB on fast bowling technique, and the younger age of the bowlers.

\section{ACKNOWLEDGEMENTS}

Head coaches-Stewart Burrows, Andy Hayhurst, and Russell Cobb-and their coaching teams of Nottinghamshire CCC, Derbyshire CCC, and Leicestershire CCC Centres of Excellence; Conor Gissane, Brunel University, for statistical guidance; the 70 young cricketers who conscientiously provided the data.

\section{Authors' affiliations}

P L Gregory, M E Batt, W A Wallace, Centre for Sports Medicine, Queen's Medical Centre, Nottingham, UK

\section{REFERENCES}

1 Stretch RA. The incidence and nature of injuries in first league and provincial cricketers. S Afr Med J 1993;83:339-42.

2 Stretch RA. The seasonal incidence and nature of injuries in schoolboy cricketers. S Afr Med J 1995;85:182-4.

3 Bellieppa PP, Barton NJ. Hand injuries in cricketers. J Hand Surg $[\mathrm{Br}]$ 1991;16:212-14.

4 Leary T, White JA. Acute injury incidence in professional county club cricketers (1985-1995). Br J Sports Med 2000;34:145-7.

5 Harris I. The prevalence of low back pain in cricketers: an undergraduate epidemiological study. South African Journal of Physiotherapy 1993;94:65-6.

6 Foster $\mathrm{DH}$, John D, Elliott B, et al. Back injuries to fast bowlers in cricket: a prospective study. Br J Sports Med 1989;23:150-4.

7 Eliott BC, Hardcastle PH, Burnett AF, et al. The influence of fast bowling and physical factors on radiological features in high performance young fast

bowlers. Sports Medicine, Training and Rehabilitation 1992;3:113-30.

8 National Cricket Coach Initiative. Hitting the seam. Birmingham: Warwickshire County Cricket, 1988;2:4-5.

9 Elliott BC, Davis JW, Khangure MS, et al. Disc degeneration and the young fast bowler in cricket. Clin Biomech 1993;8:227-34.

10 Burnett AF, Khangure MS, Elliott BC, et al. Thoracolumbar disc degeneration in young fast bowlers in cricket: a follow up study. Clin Biomech 1996;11:305-10.

11 Hardcastle $\mathbf{P}$, Annear P, Foster DH, et al. Spinal abnormalities in young fast bowlers. J Bone Joint Surg [Br] 1992;74:421-5.

12 Gregory PL, Batt ME, Wallace WA. Comparing injuries of spin and fast bowling in young cricketers. Clin J Sport Med 2002;12:107-12. 